\title{
Effect of oral prednisolone on the bronchoprotective effect of formoterol in patients with persistent asthma
}

\author{
D.C. Grootendorst*,\#, P.J. Sterk", H.G.M. Heijerman*
}

Effect of oral prednisolone on the bronchoprotective effect of formoterol in patients with persistent asthma. D. C. Grootendorst, P.J. Sterk, H. G. M. Heijerman. (C) ERS Journals Ltd 2001

ABSTRACT: Tolerance to the bronchoprotective effects by long-acting $\beta_{2}$-agonists (LAB) in patients with asthma is not prevented by inhaled corticosteroids (ICS). This study examined whether oral prednisolone can restore the bronchoprotective effects of formoterol in 24 patients with persistent asthma already treated with ICS (at least $800 \mu \mathrm{g}$ budesonide $\cdot \mathrm{day}^{-1}$ or equivalent) and $\mathrm{LAB}$, using a parallel-group design.

During a 2-week run-in period and during the study, patients used formoterol $12 \mu \mathrm{g}$ twice daily by Turbuhaler $\AA$, instead of their own LAB. At baseline and at the end of 7days treatment with oral placebo or prednisolone $\left(30 \mathrm{mg} \cdot \mathrm{day}^{-1}\right)$, provocative concentration of histamine causing a $20 \%$ fall in forced expiratory volume in one second (PC20 histamine) was measured on two separate days after randomized singledose inhalation of placebo (postP) or formoterol (postF). In addition, PC20postF was measured $24 \mathrm{~h}$ after starting oral treatment. The protective effect by formoterol at baseline and during treatment was calculated as the difference between the logs of PC20postP and PC20postF.

The mean \pm SEM in doubling dose (DD) bronchoprotective effect at baseline was $0.8 \pm 0.4 \mathrm{DD}$ in the placebo group and $1.0 \pm 0.4 \mathrm{DD}$ in the prednisolone group. At the end of the treatment period, the protective effect changed to $1.0+0.5 \mathrm{DD}$ and $0.8+0.6$ DD in the placebo and prednisolone treated groups, respectively. This change was not different between the groups $(p>0.4)$.

In conclusion, the bronchoprotective effect by formoterol is not influenced by 1 week prednisolone treatment in patients with asthma who are using regular inhaled corticosteroids and long-acting $\beta_{2}$-agonists. These findings indicate that tolerance to long-acting $\boldsymbol{\beta}_{2}$-agonists cannot be restored by oral steroid therapy.

Eur Respir J 2001; 17: 374-379.
*Dept of Pulmonology, Leijenburg Hospital, The Hague and " Leiden University Medical Centre, Leiden, the Netherlands.

Correspondence: D.C. Grootendorst, Dept of Pulmonology, Leijenburg Hospital, P.O. Box 40551, NL-2504 LN The Hague, The Netherlands Fax: 31703592150

Keywords: Bronchial hyperresponsiveness bronchoprotection

corticosteroids

long-acting $\beta_{2}$-agonists

severe asthma

tolerance

\section{Received: March 142000}

Accepted after revision October 182000

This work was supported by a grant from Astra Pharmaceutica, (Zoetermeer, the Netherlands).
Asthma is usually treated with inhaled corticosteroids (ICS), in combination with bronchodilators [1]. Inhaled $\beta_{2}$-agonists, both short- and long-acting, are the most potent bronchodilators in the treatment of asthma [2], whilst single doses of $\beta_{2}$-agonists protect against a variety of bronchoconstrictive stimuli, including methacholine, adenosine $5^{\prime}$-monophosphate, exercise and allergen [3-6]. However, evidence is accumulating that regular use of $\beta_{2}$-agonists results in a decrease in the initially large bronchoprotective effects by $\beta_{2}$-agonists [7], whilst the bronchodilating effects are sustained [8]. This so-called tolerance to the bronchoprotective effect by $\beta_{2}$-agonists appears to develop within one day of treatment with a longacting $\beta_{2}$-agonist (LAB) [9].

ICS are not effective in the attenuation of tolerance. Several studies have now shown that neither preexisting regular treatment with ICS [10-12], or concomittant start of treatment with inhaled corticosteroids combined with LAB [13] seem to prevent the development of tolerance to the bronchoprotective effects by LAB in patients with asthma. To date, the effects of oral glucocorticoids on tolerance to the bronchoprotective effects by long-acting bronchodilators have not been examined. This is relevant during asthma exacerbations, when patients are more likely to increase the use of bronchodilators and it would be interesting to know whether or not oral steroid treatment can enhance the efficacy of bronchodilators.

The aim of this study was to examine whether a short course of prednisolone $\left(30 \mathrm{mg} \cdot \mathrm{day}^{-1}\right.$ for 7 days) can reverse already existing tolerance which already exists, to the bronchoprotective effects by LAB in patients with moderate to severe persistent asthma who are using high doses of ICS in combination with LAB regularly.

\section{Methods}

\section{Patients}

Twenty-four nonsmoking patients with moderate to severe persistent asthma were selected and invited to participate in this study (table 1). In all patients, symptoms were controlled by regular treatment with 
Table 1.-Patient characteristics at entry

\begin{tabular}{lcc}
\hline & Placebo group & Prednisolone group \\
\hline Sex M:F & $5: 7$ & $2: 8$ \\
Age yrs & $40.3 \pm 8.6$ & $38.3 \pm 10.5$ \\
FEV1 \% pred & $88.6 \pm 15.9$ & $90.9 \pm 13.8$ \\
FEV1 reversibility \% pred & $8.6 \pm 6.4$ & $10.5 \pm 7.8$ \\
PC20 histamine mg $\mathrm{mL}^{-1 \#}$ & $0.42 \pm 2.0$ & $0.29 \pm 2.3$ \\
ICS $\mu \mathrm{g}^{-1}$ day $^{-1} \mathrm{n}$ & $1533.3 \pm 149.1(6)$ & $1200 \pm 400(4)$ \\
$\quad$ Budesonide & - & $800(1)$ \\
Beclomethasone dipropionate & $1250 \pm 381.9(6)$ & $1600 \pm 489.9(5)$ \\
Fluticasone dipropionate & $4 / 8$ & $3 / 7$ \\
LABD For/Sal n & &
\end{tabular}

Data are expressed as mean \pm SD. ${ }^{\#}$ : PC20 values as geometric mean \pm SD (doubling concentrations). ICS: inhaled corticosteroids; n: number of patients on this medication; LABD: long-acting inhaled bronchodilators; For: formoterol; Sal: salmeterol; FEV1: forced expiratory volume in one second; $\mathrm{PC}_{20}$ histamine: provocative concentration of histamine causing a $20 \%$ fall in FEV1.

ICS together with LAB. Ten patients were using budesonide (range $800-1600 \mu \mathrm{g}$ daily), one patient was using beclomethasone dipropionate ( $800 \mu \mathrm{g}$ daily) and 13 patients were using fluticasone dipropionate (range $1000-2000 \mu \mathrm{g}$ daily). In addition, all patients used short-acting $\beta_{2}$-agonists as a rescue medication. Treatment with ICS and LAB had been stable during the past six months or longer. Forced expiratory volume in one second (FEV1) was $>60 \%$ predicted [14] and reversible by $>12 \%$ pred or within the normal range after bronchodilation $(400 \mu \mathrm{g}$ inhaled salbutamol) in all patients. Furthermore, all subjects were hyperresponsive to histamine, as shown by a provocative concentration causing a $20 \%$ fall in FEV1 $(\mathrm{PC} 20)<4 \mathrm{mg} \cdot \mathrm{mL}^{-1}$ [15]. None of the patients had suffered from a respiratory tract infection in the 2 weeks prior to the study, nor had they been treated with oral prednisolone in the 3 months before the study. The study was approved by the Hospital Medical Ethics Committee. Written informed consent was obtained from all patients.

\section{Design}

This was a double-blind, randomized, placebocontrolled, parallel group study (fig. 1). Inclusion

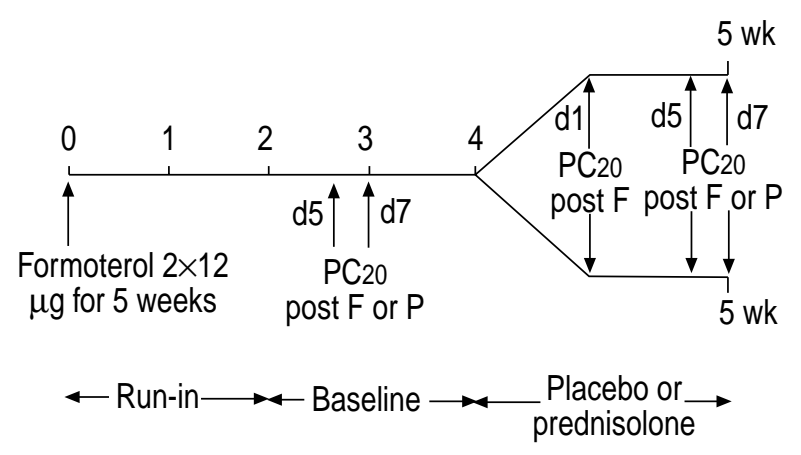

Fig. 1. - Design of the study. The horizontal axis shows the weeks during the study. d5: day 5; d7: day 7; F: pretreatment with inhaled formoterol; P: pretreatment with placebo inhalation. PC20: provocative concentration causing a $20 \%$ fall in forced expiratory volume in one second. criteria were assessed on 2 separate days, after which the patients enrolled to the run-in period and were instructed to use a formoterol Turbuhaler $\mathbb{R}(12 \mu \mathrm{g}$ per metred dose, Oxis $\AA$ Turbuhaler $\AA$, Astra, Sweden) twice daily, instead of their own long-acting bronchodilator for the duration of the study. After the two weeks run-in period, patients entered a 2 week baseline period. At days 5 and 7 of the baseline period, PC20 histamine was measured $30 \mathrm{~min}$ after single dose inhalation of placebo or formoterol $(12 \mu \mathrm{g})$ in a double-blind fashion, administered in randomized order. After completion of the baseline period, patients were randomized to use either prednisolone $30 \mathrm{mg}$ or identical placebo tablets for 7 consecutive days. At $24 \mathrm{~h}$ after administration of the first dose of oral treatment (placebo or prednisolone $30 \mathrm{mg}$ ), PC20 histamine was measured $30 \mathrm{~min}$ after (single-blind) inhalation of formoterol $(12 \mu \mathrm{g})$. At days 5 and 7 of the oral treatment period, PC20 histamine was again obtained $30 \mathrm{~min}$ after double-blind, randomized, single dose inhalation of placebo or formoterol $(12 \mu \mathrm{g})$, the order of which being the same as during the baseline period (fig. 1). The order of formoterol and placebo inhalation was randomized per oral treatment group.

Lung function measurements for each patient were performed at the same time of day $\pm 2 \mathrm{~h}$. Patients were instructed to use the oral treatment before breakfast, lunch or dinner, whichever was closest to their time of lung function measurement. In that way, the oral treatment was taken at $24 \pm 2 \mathrm{~h}$ before lung function measurements. Patients withheld their formoterol for $24 \mathrm{~h}$ before each study visit, and short-acting bronchodilators for $8 \mathrm{~h}$. They continued usage of their regular ICS throughout the study in the morning and evening, as usual, with no change in the dosage of ICS. Furthermore, patients were asked to refrain from caffeine-containing beverages for $4 \mathrm{~h}$ before each visit.

\section{Spirometry and challenge tests}

FEV1 was recorded from standardized maximal expiratory flow/volume curves using a calibrated Masterlab pneumotachograph (Jaeger, Würzburg, Germany). Spirometric reversibility was determined 
by measuring FEV1 before and 15 min after inhalation of $400 \mu \mathrm{g}$ salbutamol, administered by a metred dose inhaler (MDI) connected to an aerosol chamber, and expressed as an increase in FEV1 in \% pred.

Bronchial hyperresponsiveness to histamine was measured using the 2 min tidal breathing method [15]. Serial doubling concentrations of histaminediphosphate $\left(0.03-32 \mathrm{mg} \cdot \mathrm{mL}^{-1}\right)$ were administered to the patient by a DeVilbiss 646 nebulizer (DeVilbiss Co., Somerset, PA, USA) at 5 min intervals. The response to histamine was measured by FEV1 at 30 and $90 \mathrm{~s}$ after inhalation of each concentration. Challenge tests were discontinued if FEV1 fell by $>20 \%$ from baseline, or if the highest concentration of histamine had been administered. After completion of each challenge test, $400 \mu \mathrm{g}$ of salbutamol was given to the patient.

\section{Statistical analysis}

PC20 values were calculated by linear interpolation of the last two points on the log concentration-response curve. If FEV 1 had not fallen by $>20 \%$ from baseline after administration of the highest concentration of histamine, PC20 was censored to $64 \mathrm{mg} \cdot \mathrm{mL}^{-1}$ (which was necessary on 2 occasions). All PC20 values were (natural) log-transformed before statistical analysis. Data are presented as mean \pm SD and PC20 values as geometric mean \pm SD in doubling concentrations. The protective effect by formoterol at baseline and during the treatment period was calculated as the difference between postformoterol $\mathrm{PC}_{20}$ and postplacebo PC20, expressed in doubling concentrations. The change in protective effect of formoterol on $\mathrm{PC}_{20}$ histamine during the study was defined as the difference between the protective effect of formoterol during treatment compared to the baseline period, expressed in doubling concentrations of histamine. Between-group differences in parameters were tested by an unpaired t-test. Withingroup changes were tested by repeated measured analysis of variance (MANOVA) and then by a paired t-test. Statistical analyses were performed using the Statistical Package for Social Sciences (SPSS Inc., Chicago, IL, USA). A probability value of $<5 \%$ was considered statistically significant.

With the sample size used in this study (12 subjects in each treatment arm), $\alpha=0.05$ (two-sided), $\beta=0.10$ (one-sided; power $=80 \%$ ) and the standard deviation in bronchoprotective effect in the study group at baseline (1.8), the study was powered to detect a difference in bronchoprotective effect of 2 doubling concentrations of histamine between the placebo and prednisolone treated patients.

\section{Results}

Twenty-two patients completed the study. Two patients in the prednisolone group were withdrawn; one because of a nonrespiratory illness during the study, and one because of a protocol violation. At inclusion, the patients in the prednisolone and placebo group did not differ in relevant magnitude with respect to age, FEV1, reversibility in FEV1, $\mathrm{PC}_{20}$ histamine and dosage of ICS (table 1).

Prechallenge FEV1 did not change by prednisolone or placebo treatment $(\mathrm{p}>0.2$, table 2$)$. PC20 after single-dose formoterol and placebo inhalation, during oral placebo and prednisolone treatment are shown in table 3. The postplacebo PC20 and postformoterol PC20 were not different within and between the prednisolone and placebo treated groups at any of the visits $(p>0.3)$. However, postformoterol PC20 tended to be improved at $24 \mathrm{~h}$ after starting prednisolone treatment $(\mathrm{p}=0.08$ compared to postformoterol PC20 at baseline).

The bronchoprotective effect by formoterol, i.e. difference between $\mathrm{PC}_{20}$ after formoterol and placebo inhalation expressed in doubling concentrations, was not different between the prednisolone and placebo groups at baseline $(p>0.8)$, and did not change within and between the groups during treatment $(\mathrm{p}>0.5$, fig. 2). Finally, the mean ( $95 \%$ confidence interval) change in bronchoprotective effect by formoterol was not significantly different between the two treatment groups $(p>0.4)$, being 0.14 doubling dose (DD) $(-0.54-0.82)$ in the placebo group and -0.14 DD $(-0.97-0.68)$ in the prednisolone group.

\section{Discussion}

The results of this study show that in patients with moderate to severe persistent asthma, treated with

Table 2. - Forced expiratory volume in one second expressed as \% predicted, before and after inhalation of placebo or formoterol, in the oral placebo and prednisolone group during the study

\begin{tabular}{|c|c|c|c|c|c|}
\hline & \multicolumn{2}{|c|}{ Placebo inhalation } & \multicolumn{3}{|c|}{ Formoterol inhalation } \\
\hline & Baseline $\mathrm{d} 5 / 7$ & Treatment $\mathrm{d} 5 / 7^{\#}$ & Baseline d5/7 & Treatment d 1 & Treatment d5/7* \\
\hline \multicolumn{6}{|l|}{ Oral placebo } \\
\hline Preinhalation & $88.7 \pm 3.7$ & $88.5 \pm 4.4$ & $90.0 \pm 4.2$ & $87.1 \pm 4.9$ & $88.9 \pm 4.3$ \\
\hline Postinhalation & $89.9 \pm 3.3$ & $89.3 \pm 4.2$ & $95.2 \pm 4.0$ & $92.5 \pm 4.6$ & $93.4 \pm 3.8$ \\
\hline \multicolumn{6}{|l|}{ Prednisolone } \\
\hline Preinhalation & $95.5 \pm 4.1$ & $91.5 \pm 3.8$ & $92.5 \pm 3.8$ & $92.4 \pm 4.6$ & $93.6 \pm 4.4$ \\
\hline Postinhalation & $98.5 \pm 4.2$ & $92.0 \pm 4.4$ & $97.8 \pm 3.6$ & $98.4 \pm 4.0$ & $97.7 \pm 4.9$ \\
\hline
\end{tabular}

Data are presented as mean \pm SEM. ${ }^{\#}: \mathrm{d} 5 / 7$ : double-blind, randomized pretreatment with placebo or formoterol inhalation was administered to the patient on days 5 and 7 of the baseline and oral treatment period. The randomization order was the same during the two periods. 
Table 3. - Provocative concentration of $\mathrm{PC}_{20}$ histamine causing a $20 \%$ fall in forced expiratory volume in one second after placebo and formoterol pretreatment during the baseline and treatment period in the placebo and prednisolone group

\begin{tabular}{|c|c|c|c|c|c|}
\hline & \multicolumn{2}{|c|}{ Placebo inhalation } & \multicolumn{3}{|c|}{ Formoterol inhalation } \\
\hline & Baseline $\mathrm{d} 5 / 7^{\#}$ & Treatment $\mathrm{d} 5 / 7^{\#}$ & Baseline $\mathrm{d} 5 / 7^{\#}$ & Treatment d1 & Treatment $\mathrm{d} 5 / 7^{\#}$ \\
\hline Oral placebo & $0.8 \pm 0.7$ & $0.8 \pm 0.6$ & $1.5 \pm 0.6$ & $1.9 \pm 0.5$ & $1.6 \pm 0.6$ \\
\hline Prednisolone & $0.8 \pm 0.8$ & $1.0 \pm 0.7$ & $1.7 \pm 0.8$ & $3.0 \pm 0.8^{\circ}$ & $1.8 \pm 0.8$ \\
\hline
\end{tabular}

Data are presented as geometric mean \pm SEM in doubling concentrations. ${ }^{*}: \mathrm{d} 5 / 7$ : double-blind, randomized pretreatment with placebo or formoterol inhalation was administered to the patient on days 5 and 7 of the baseline and oral treatment period. The randomized order was the same during the two periods; ${ }^{\uparrow}: p=0.08$ compared to postformoterol $\mathrm{PC}_{20}$ during baseline.

regular ICS and LAB, addition of oral prednisolone $30 \mathrm{mg} \cdot \mathrm{day}^{-1}$ for 7 days does not improve the bronchodilator and bronchoprotective effects by formoterol. However, PC20 to histamine after formoterol inhalation tended to be temporarily increased at $24 \mathrm{~h}$ after the first dose of prednisolone, as compared to postformoterol PC20 at baseline. These findings suggest that one week of treatment with oral prednisolone does not restore the bronchoprotective effects of formoterol, nor does it influence the bronchodilating effects of formoterol in patients with moderate to severe persistent asthma using regular ICS in combination with long-acting bronchodilators.

This is the first study demonstrating that the bronchoprotective effect by the LAB formoterol is not affected by 7-days of treatment with oral prednisolone $(30 \mathrm{mg})$ in patients with asthma who are already treated with high doses of inhaled corticosteroids and long-acting bronchodilators. However, prednisolone exhibited some acute effects, since at $24 \mathrm{~h}$ after starting oral treatment the postformoterol PC20 tended to be increased by almost two doubling concentrations of histamine from baseline postplacebo $\mathrm{PC} 20$, as compared to one doubling concentration in the placebo group. Remarkably, this change in postformoterol PC20 was not maintained during continued treatment with prednisolone and formoterol, since at the end of the treatment period neither the level nor the shift in postformoterol PC20 appeared to be different from the values at baseline or from the placebo group.

The present results were obtained using a standar-

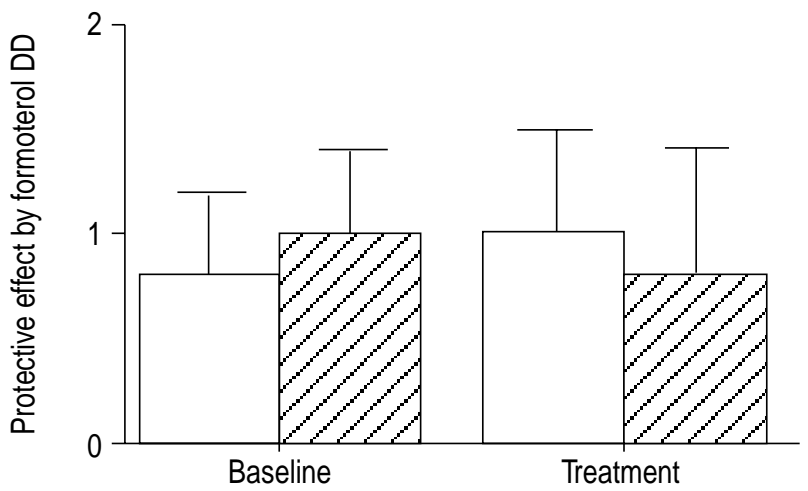

Fig. 2. - Mean \pm SEM protective effect by formoterol, calculated as difference between provocative concentration causing a $20 \%$ fall in forced expiratory volume in one second (PC20) postformoterol and $\mathrm{PC}_{20}$ postplacebo inhalation, in doubling concentrations at baseline and during the treatment period in the placebo $(\square)$ and prednisolone $(\mathbb{Z})$ treated groups. dized and validated method to measure bronchial hyperresponsiveness [15]. Furthermore, first, nonsmoking patients with asthma, controlled by high doses of inhaled steroids and LAB were selected. All patients had stable disease, and had no change in their medication during the past months. It is likely that the patients had already established tolerance to the bronchoprotective effect by their own long-acting bronchodilator, since they used LAB regularly $[10$, $12,13]$. However, given the present objective and study design, the degree of the pre-existing bronchoprotective effect could not be established, since this would have required discontinuation of regular LAB therapy. To ensure that all patients had an adequate duration of treatment by formoterol, they participated in a 2-week run-in period, before entering the baseline period of the study. This design succeeded in inducing tolerance since the bronchoprotective effect by single-dose formoterol at baseline was less than one doubling concentration of histamine, which is far less than that observed in patients not treated by regular LAB [6] and comparable to the residual bronchoprotective effect after a few weeks of such treatment $[7,12,13]$. Second, to study the short-term effects of oral prednisolone on bronchoprotection bronchial hyperresponsiveness to histamine was also measured after formoterol inhalation at $24 \mathrm{~h}$ after starting oral treatment. It would have been interesting to have paired measurements of bronchial hyperresponsiveness to histamine at this timepoint after inhalation of placebo and formoterol, as was done at baseline and during the treatment period, in order to examine the acute effects of prednisolone on the bronchoprotective effects by formoterol. However, PC20 measurements after randomized pretreatment could not be performed on the same day due to the duration of action of formoterol. Furthermore, the authors wanted to be sure that all subjects had used at least 2 doses of formoterol in the period before the PC20 measurement since this has been shown to induce tolerance [9]. Third, PC20 histamine was measured at $30 \mathrm{~min}$ after single-dose inhalation since formoterol has a relatively rapid onset of action (within $15 \mathrm{~min}$ ) [16], with an optimal protective effect coinciding with the time of the histamine challenge. Finally, the dose of prednisolone, (30 mg per day for one week) chosen in this study was based on the current recommendations for the treatment of acute exacerbations of asthma [1]. Therefore, this enabled the examination of whether or not conventional treatment of an asthma exacerbation can improve the bronchoprotective (and bronchodilating) effect of bronchodilators, the most potent rescue medication in an exacerbation. 
What are the mechanisms underlying the results? With prolonged usage of $\mathrm{LAB}$, and prolonged $\beta_{2^{-}}$ receptor occupancy, downregulation of the $\beta_{2}$-receptor is likely to occur [17], through uncoupling of the receptor from the membranous $\mathrm{G}_{\mathrm{s}}$ protein, internalization of the receptor, a decline in steady state $\beta_{2}$-receptor messenger ribonucleic acid (mRNA) and/or reduced transcription [18-20]. Such downregulation or uncoupling of $\beta_{2}$-receptor numbers can be reflected by a reduced protective effect of LAB against bronchoconstrictor stimuli such as methacholine [7] and exercise [4]. Following treatment with high dose intravenous glucocorticoids, an upregulation of $\beta_{2}$-receptor numbers on circulating lymphocytes, due to increased transcription [21], can be observed in patients with asthma within hours of the start of treatment [22]. This is in keeping with the present results which show a trend towards an increase in PC20 after formoterol inhalation at $24 \mathrm{~h}$ after the start of prednisolone treatment, compatible with $\beta_{2}$-receptor upregulation. With continued use of oral glucocorticoids and LAB, $\beta_{2}$-receptor numbers may again be downregulated, resulting in renewed development of tolerance to the bronchoprotective effect by long-acting bronchodilators, as shown by the lack of difference between the bronchoprotective effect by formoterol before and after a week treatment with oral prednisolone.

What are the clinical implications of the study? Longacting $\beta_{2}$-agonists are indicated in the treatment of patients with moderate and severe persistent asthma for relief of symptoms [1]. With continued use of longacting $\beta_{2}$-agonists, these patients develop tolerance to the bronchoprotective effect of these drugs [7], which is not prevented by concomitant treatment with inhaled corticosteroids [10-13], oral theophylline [23], or oral glucocorticoids. Furthermore, exposure to allergens may result in $\beta_{2}$-receptor dysfunction [24], possibly on top of the existing downregulated $\beta_{2}$-receptor numbers [17]. Thus, in case of an allergen-induced asthma exacerbation, $\beta_{2}$-agonists may not be effective due to receptor downregulation and dysfunction, while at the same time patients are more likely to increase their use of bronchodilators. Although a short course of oral glucocorticoids is very effective in improving symptoms and reducing airway inflammation during an acute exacerbation [25], it does not reverse tolerance to the protective effects of $\beta_{2}$-agonists. This phenomenon needs further ex vivo examination of $\beta_{2}$-receptor numbers on circulating lymphocytes, or, preferably, on human bronchial smooth muscle.

\section{References}

1. National Heart Lung Blood Institute. National Asthma Education and Prevention Program. Expert Panel Report 2: Guidelines for the diagnosis and management of asthma. NIH publication no. 97-4051. Bethesda MD, 1997.

2. Nelson HS. $\beta$-adrenergic bronchodilators. $N$ Engl J Med 1995; 333: 499-506.

3. O'Connor BJ, Fuller RW, Barnes PJ. Nonbronchodilator effects of inhaled $\beta_{2}$-agonists. Greater protection against adenosine monophosphate than methacholine-induced bronchoconstriction in asthma. Am J Respir Crit Care Med 1994; 150: 381-387.

4. Ramage L, Lipworth BJ, Ingram CG, Cree IA, Dhillon DP. Reduced protection against exercise induced bronchoconstriction after chronic dosing with salmeterol. Respir Med 1994; 88: 363-368.

5. Pizzichini MMM, Kidney JC, Wong BJO, et al. Effect of salmeterol compared with beclomethasone on allergen-induced asthmatic and inflammatory responses. Eur Respir J 1996; 9: 449-455.

6. Taylor DA, Jensen MW, Aikman SL, Harris JG, Barnes PJ, O'Connor BJ. Comparison of salmeterol and albuterol-induced bronchoprotection against adenosine monophosphate and histamine in mild asthma. Am J Respir Crit Care Med 1997; 156: $1731-1737$.

7. Cheung D, Timmers MC, Zwinderman AH, Bel EH, Dijkman JH, Sterk PJ. Long-term effects of a longacting $\beta_{2}$-adrenoceptor agonist, salmeterol, on airway hyperresponsiveness in patients with mild asthma. $N$ Engl J Med 1992; 327: 1198-1203.

8. Arledge TE, Liddle R, Stahl E, Rossing TH. Salmeterol does not cause tolerance during longterm asthma therapy. J Allergy Clin Immunol 1996; 98 : $1116-1119$.

9. Drotar DE, Davis EE, Cockcroft DW. Tolerance to the bronchoprotective effect of salmeterol 12 hours after starting twice daily treatment. Ann Allergy Asthma Immunol 1998; 80: 31 - 34.

10. Booth H, Bish R, Walters J, Whitehead F, Walters EH. Salmeterol tachyphylaxis in steroid treated asthmatic subjects. Thorax 1996; 51: 1100-1104.

11. Kalra S, Swystun VA, Bhagat R, Cockcroft DW. Inhaled corticosteroids do not prevent the development of tolerance to the bronchoprotective effect of salmeterol. Chest 1996; 109: 953-956.

12. Boulet L-P, Cartier A, Milot J, Co̊té J, Malo J-L, Laviolette M. Tolerance to the protective effects of salmeterol on methacholine-induced bronchoconstriction: influence of inhaled corticosteroids. Eur Respir $J$ 1998; 11: $1091-1097$.

13. Yates DH, Kharitonov SA, Barnes PJ. An inhaled glucocorticoid does not prevent tolerance to the bronchoprotective effect of a long-acting $\beta_{2}$-agonist. Am J Respir Crit Care Med 1996; 154: 1603-1607.

14. Quanjer PhH, Tammeling GJ, Cotes JE, Pedersen OF, Peslin R, Yernault J-C. Lung volumes and forced ventilatory flows. Report working party standardization of lung function tests European Community for Steel and Coal. Eur Respir J 1993; 6: Suppl. 16, 5-40.

15. Sterk PJ, Fabbri LM, Quanjer $\mathrm{PhH}$, et al. Airway responsiveness. Standardized challenge testing with pharmacological, physical and sensitizing stimuli in adults. Report working party standardization of lung function tests European Community for Steel and Coal. Eur Respir J 1993; 6: Suppl. 16, 53-83.

16. Palmqvist M, Persson G, Lazer L, Rosenborg J, Larsson P, Lötvall J. Inhaled dry-powder formoterol and salmeterol in asthmatic patients: onset of action, duration of effect and potency. Eur Respir J 1997; 10: 2484-2489.

17. Newnham DM, Grove A, McDevitt DG, Lipworth BJ. Subsensitivity of bronchodilator and systemic $\beta_{2}$ adrenoceptor responses after regular twice daily treatment with eformoterol dry powder in asthmatic patients. Thorax 1995; 50: 497-504.

18. Nishikawa M, Mak JCW, Shirasaki H, Barnes PJ. 
Differential down-regulation of pulmonary $\beta_{1}$ - and $\beta_{2}$ adrenoceptor messenger RNA with prolonged in vivo infusion of isoprenaline. Eur J Pharmacol ( $M o l$ Pharmacol) 1993; 247: $131-138$.

19. Nishikawa M, Mak JCW, Shirasaki H, Harding SE, Barnes PJ. Long-term exposure to norepinephrine results in down-regulation and reduced mRNA expression of pulmonary $\beta$-adrenergic receptors in guinea pigs. Am J Respir Cell Mol Biol 1994; 10: 91 99.

20. Barnes PJ. Beta-adrenergic receptors and their regulation. Am J Respir Crit Care Med 1995; 152: $838-860$.

21. Mak JCW, Nishikawa M, Barnes PJ. Glucocorticosteroids increase $\beta_{2}$-adrenergic receptor transcription in human lung. Am J Physiol 1995; 268: L41-L46.

22. Tan KS, Grove A, McLean A, Gnosspelius Y, Hall IP,
Lipworth BJ. Systemic corticosteroid rapidly reverses bronchodilator subsensitivity induced by formoterol in asthmatic patients. Am J Respir Crit Care Med 1997; 156: $28-35$.

23. Cheung D, Wever AMJ, de Goeij JA, de Graaff CS, Steen H, Sterk PJ. Effects of theophylline on tolerance to the bronchoprotective actions of salmeterol in asthmatics in vivo. Am J Respir Crit Care Med 1998; 158: $792-796$.

24. Song P, Milanese M, Crimi E, Rehder K, Brusasco V. Allergen challenge of passively sensitized human bronchi alters $\mathrm{M}_{2}$ and $\beta_{2}$ receptor function. $A m$ J Respir Crit Care Med 1997; 155: 1230-1234.

25. Pizzichini MMM, Pizzichini E, Clelland L, et al. Sputum in severe exacerbations of asthma. Kinetics of inflammatory indices after prednisone treatment. Am J Respir Crit Care Med 1997; 155: 1501 - 1508. 